\title{
Rethinking Urban Space: GPS Drawing as a Tool to Examine Spatial Patterns and Relationships
}

\author{
Thomas SCHAUPPENLEHNER, Anna HÖGLHAMMER, \\ Andreas MUHAR and Renate EDER \\ BOKU, Vienna/Austria ·thomas.schauppenlehner@boku.ac.at \\ This contribution was double-blind reviewed as full paper.
}

\begin{abstract}
In a research project on the spatial behaviour of young people we implemented the idea of creating temporary artworks and messages using physical space itself as a drawing surface. We conducted GPS drawing actions with secondary school students in the city of Vienna. In small groups, students developed concepts for their pieces of GPS art during the arts class at school and were later asked to draw this idea "into the city" by walking a GPS track. The contents of their work provide a valuable insight into the perception and meaning of space from a different point of view. By using a simple GPS device as a "pen" and a cityscape as the corresponding "paper" the students interacted with space in a new way. They experienced different facets of familiar spatial settings and places and thus also rethought these spaces in a new way.
\end{abstract}

\section{Introduction}

Most of us have drawn images or letters with fingers in sand sometimes - small pieces of temporary art and messages representing the feelings and ideas in a single moment, at a single place and with site-specific materials and conditions. Created for ourselves, our friends and families or people coming around later and visible often only for a couple of minutes or hours.

Site conditions, spatial characteristics and on-site materials are also used by many contemporary land art artists like Andrew Rogers, James Turrell, Michael Heizer, Robert Smithson or Andy Goldsworthy. They use spatial settings to create - often large-scale - artwork and land art sculptures and drawings. They work outdoors, with material from the landscape which gave their creations a meaning. Time, change and place attachment often form the focus of such artwork (GOLDSWORTHY \& FRIEDMAN 2008). The natural dynamics gradually modify these objects. While some interventions can persist over even a very long time span, such as the famous Nazca Lines in Southern Peru, most pieces of land art are rather designed to disappear after a while (URSPRUNG 2003).

The concept of creating artwork through walking was introduced by artists like Hamish Fulton or Richard Long (ROELSTRAETE 2010, TUFNELL et al. 2002) and later expanded into GPS drawing by Hugh Pryor and Jeremy Wood (LAURIAULT \& WOOD 2009). GPS drawing 
follows the idea of creating large-scale artworks within and depending on a specific landscape with the help of new media and technology. In contrast to land art, GPS drawings appear only digitally in form of tracks and waypoints without leaving any traces or marks in the real landscape, however, they act as a proof that the artist has physically been there. Thus there is a significant difference between a GPS track displayed on top of a map and a line drawing sketched on a map. Differing from physical land art, however, longevity might be established over longer periods of time.

\section{Mapping, GPS Technologies and Spatial Citizenship}

GPS technology is more and more entering into our daily life at different stages and levels. In spatial research, GPS devices can be used to gain data for understanding people's spatial behaviours as they are an interactive device, to express and document individual or collective experiences and perceptions of space. As PARKS (2001) points out, it can be used as a tool - similar to documentation practices such as photography and movies - , "to make visible the structures of everyday life and to encourage wandering within and beyond the architecture of the city, redefining the lines, patterns and routines of the economic, social and political infrastructure" (PARKS 2001). But unlike in photography and movies, GPS devices trace the human motion more abstractly in form of waypoints and personal plots - a basis for the creation of personal maps and geographies.

In a traditional notion, maps help to understand and communicate about the environment and like writing they are "a way of graphically expressing mental concepts and images" (ROBINSON \& PETCHENIK 1976). Following a more recent approach inspired by critical cartography and critical GIS, maps can be deemed social constructions regarding the meaning of spaces. These are intentionally produced to make others understand spatial meanings in the way a map author wants them to be understood (HARLEY 1989).

Using GPS technologies can help citizens to reflect that they 'write' with their bodies in the urban surrounding and beyond that to become active readers of the landscape they are in (PARKS 2001). A basic, non-art based concept in this context has been proposed by STARK (2012), that allows students to record their writing in space, and reflect on it. To become active readers could also be seen an important step supporting spatial citizenship education.

Spatial citizenship education aims at enabling individuals to critically appropriate space and reflect about its' meanings in society. For this, technical, practical and emancipatory learning approaches are needed. GI(S)-based education in schools is contributing to this by supporting spatial thinking using GIS and trying to address all three learning approaches. So far mostly the technical competences were represented in curricula, however, GRYL et. al. (2010) emphasize that "it is necessary to enable students to deconstruct meanings of space in geomedia with respect to its subjective and discursive background and to communicate their own world views as an expression of their democratically negotiated emancipatory interests".

Our GPS drawing approach provides a method to connect technical, practical and emancipatory learning approaches in a creative way. The idea is to use GPS devices like a pen and a landscape as the corresponding piece of paper to draw one's personal map, opinion or perception of spaces in the urban landscape. 
This article presents a case study on GPS drawing conducted with school students on the urban fabric of Vienna. The goal was to apply a new way to understand and read their everyday life environment by developing images and messages with the help of GPS technology combined with art.

\section{Project Framework and Pedagogical Concept}

The GPS drawing was performed within "I AM HERE!" (iamhere.boku.ac.at), a researcheducation cooperation project funded by the Austrian Federal Ministry of Science and Research within the research programme "Sparkling Science". The prior goal of "I AM HERE!" is to identify and analyse the spatial behaviour of adolescent people in the city of Vienna (SCHAUPPENLEHNER et al. 2011).

To operationalise the research topics we use different approaches like GPS tracking, online mapping and workshops to analyse current and future demands. The decision to use a broad mix of methods relies on the fact, that it is challenging for many people to describe and evaluate their everyday life environment, as it is not explicit in their mind - they just use it (SCHAUPPENLEHNER et al. 2012). Therefore, we provide a set of different methods as "spectacles", that people can choose from to look at their cityscape in a specific way.

The work with the school students is based on a constructivist model of learning (VYGOTSKY 1978, VON FoERSTER 2003, AHAMER \& RAUCH 2006), where students take an active part and create knowledge through their own experience. The advantage of this model is that learning is seen as an active process that starts from learner's pre-conceptions and interests. This pedagogical concept was supported by an interactive teaching method, especially through the method of instructional conversations, where students gain ideas through open-ended discussions. This participatory research approach offer a useful method to improve the student's understanding of the imparted knowledge and their technical skills (MitCHELL \& ELWOOD 2012).

\section{The GPS-Drawing Project}

School students working with new technologies need a simple and straight concept to prevent frustration and project derogation (SCHAUPPENLEHNER et al. 2011). Austrian School students have a tight time schedule so we linked our project to scheduled classes. We organised workshops on how to use GPS devices and also used the well-established Scribble Maps utility (www.scribblemaps.com/maps) for a quick import and presentation of the different projects in the Google Earth environment without the need of special GIS and GPS skills. Another important aspect was to provide sufficient time for the students to discuss and reflect their ideas and experiences.

\subsection{Developing concepts for GPS art projects}

Together with an arts teacher, secondary students developed a concept for their piece of art in the urban fabric during the school lessons of one term. The concept included a map, 
where the groups marked the tracks of their artworks, and a description sheet containing title, explanations and motifs. The students learned about different land art artists and their ideas and inspirations, and were encouraged to develop own ideas to say something for, with or about the city of Vienna or a part of it. Within small working groups, they sketched their drafts and ideas on city maps and described their ideas in a small report.

\subsection{Using GPS devices as a pen}

Before the onsite drawing session, we organised a short workshop in the school to discuss the possibilities and restrictions of GPS technology. When looking on a GPS device as a drawing instrument, one needs to consider some specific techniques to bring ideas to reality as desired. One important aspect in this context is the speed of movement to control the straightness and clarity of a stroke. This is analogue to drawing on paper - the faster the drawing speed, the straighter and clearer the stroke. Walking around slowly allows drawing more details and tighter curves, but may also lead to scrawls and scribbles, caused by irregular movements and, of course, by the GPS signal fluctuation (see Fig 1). Increasing the drawing speed leads to straighter and clearer lines, therefore different forms of transportation (e.g. public transport, bicycles, cars, etc.) can be used to set different accents.
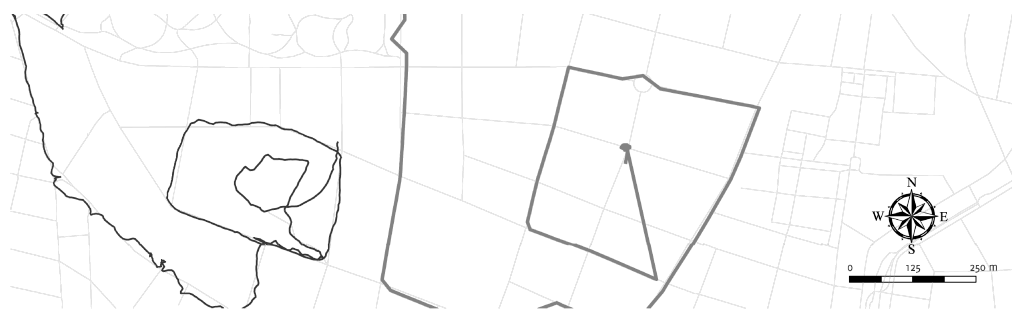

Fig. 1: The effect of different drawing speed: The thin black line on the left side was created by walking, the thick grey line on the right by riding a motorbike

It may be a concept to draw an image without a break (WOOD 2010), but sometimes it can be necessary to stop drawing and move to another location to continue. This can be solved by stopping the track recording temporarily and starting again at a new location.

The most significant restriction of the GPS technology is the requirement of a connection to the open sky, therefore some urban structures like indoor facilities or generally the underground (U-Bahn) are not accessible with this approach.

\subsection{From the paper draft to the real environment}

For transforming the conceptual ideas to the real sites we organised a one-day workshop at the university. In the beginning, every group presented their idea and we discussed thematic contents and issues regarding the feasibility as well as possible problems like scale and complexity issues. Then, the groups started - equipped with GPS devices, their plans and ideas - the GPS drawing on their selected urban site. 


\section{Results}

All projects were presented as simple line artwork in Scribble Maps superposed on different base layers from Google maps to provide a common basis for the joint discussion of the results.

\subsection{General experiences}

When it came to draw the conceptual ideas with the GPS devices, two groups had to simplify or rescale their idea. One group underestimated scales and distances with the effect that they did not have enough time to draw the whole idea in the intended way. These students got the impression of a much larger city than assumed before. One group was really surprised about the steep slopes and the significant altitude differences in their well-known surroundings. Another group had to redefine respectively reshape their concept because they simply lost orientation. Following a drawn line on a map in a dense urban setting is not that easy when one is not experienced in navigating and reading maps. These students experienced that they are not as familiar with their daily used environment as they thought before.

Nevertheless, as we had discussed this scale issue in the beginning most groups were able to draw their ideas into the city. While the students walked mainly through areas well familiar to them, they reported that they had seen some things differently or discovered new details and aspects. Some found new parks or other green spaces and recognised that not all of these spaces are open or accessible at any time. As people generally use the most efficient and convenient way to come from A to B, GPS drawing forces them to use the ways that are necessary to draw their idea. This offers also new experiences about the relief and the topography of the urban landscape.

\subsection{Selected project examples}

The project "footprints" had the intention to impose footprints of different scales on the city of Vienna to show different relations and spatial meanings of several regions. While a small footprint was written into the group's daily used space, the inner city of Vienna was surrounded by a large representation of a footprint. The large footprint was drawn using both public transportation and walks. The project shows preferred locations and the distances between them.

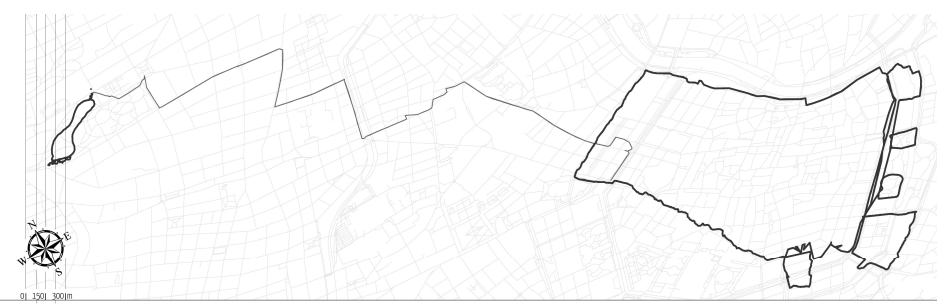

Fig. 2: Footprints with a connection between (Anja Heger, Jenny Daxböck \& Antonia Hofstädter) 
One group decided to write the acronym "YOLO" - which means "You Only Live Once" as picture mark in form of a smiley (see Fig. 3 above). The reason for this motif was that this quote represents good maxim for their life. As "YOLO" has been identified as the German youth word of the year 2012 (DER STANDARD 2012) it seams to be a desirable mantra for life among many young people but is also described as "Excuse for young people to do dumb shit" (URBAN DICTIONARY 2012). They split up in two groups to draw "YO" and "LO" and tried not to lift up the pen within their group. This, and the fact that typically streets don't follow a straight raster for drawing letters, make the term "YOLO" not that easy to recognize (see Fig. 4). The line below "YOLO" illustrates the mouth of the smiley.

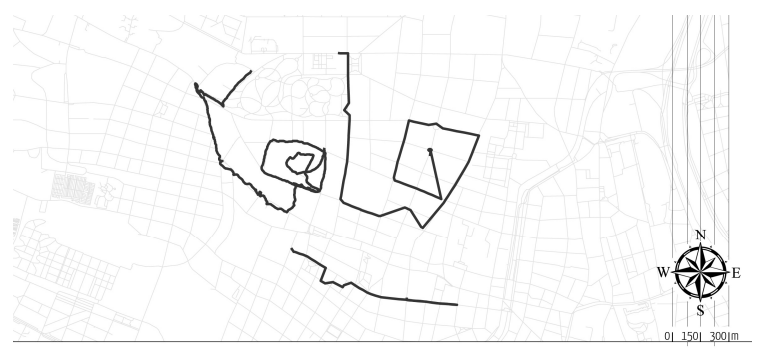

Fig. 3: The acronym "YOLO" as word and figurative mark in form of a smiley (Julian Tsolakis, Christoph Speiser, Nikolaus Knehs \& Alonso Kausel)

Another group also decided to draw a face but without the intention to create a word and figurative mark. So they paid more attention on the facial expression and proportions. The group called it the "Viennese monster" and it was intended to point out the dark side of Vienna but also represents desperation, fear and destruction (see Fig. 4). The first idea was different to the final image, because the group had some difficulties to find the route and had barriers like a closed park on their way. The result was a rather "damaged" eye but this gave the face a more demonic expression by accident.

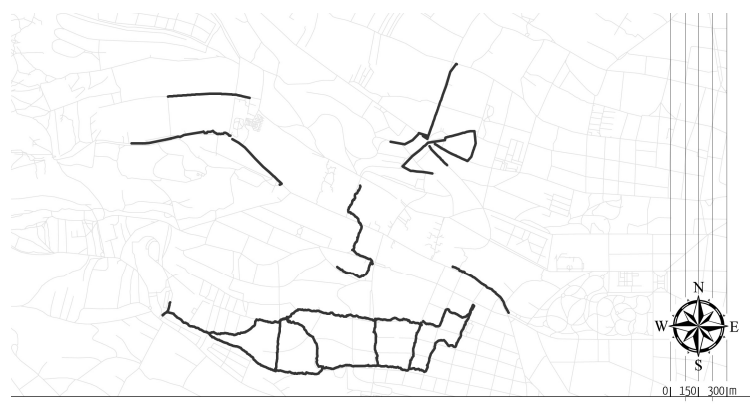

Fig. 4: The Viennese monster (Lara Fisoglou, Hannah Ertl \& Denise Seipl) 


\section{Conclusion and Outlook}

Our art project with the students pointed out very plainly that GPS drawing can lead to an intensive and different experience of the urban environment and specific spatial settings. It offers the possibility to discover new spots and peculiarities of an actually well-known area. The students found hidden places, unknown viewpoints and recognised existing barriers and topographies in a different way. This initiates a rethinking process of the daily used urban environment.

As it is often not easy for people to talk about or describe their everyday surroundings, GPS drawing can be an effective method to give people a tool to express their understanding of and feeling about a specific location or place. Therefore, GPS drawing can be an appropriate method to stimulate discussions about aspects of urban space among school students. Students, for example were confronted with meanings inscribed into space by other stakeholders, and rules that did not allow them to use space that was physically feasible to use. GPS technology has the potential to become a tool in GI-based education, stimulating the users' technical, practical and particularly emancipatory knowledge.

The GPS drawing project has been a first attempt that needs further development of teaching strategies and evaluation of learning outcomes. First insights suggest that such a project can be successful, if the students are well prepared and educated regarding the artistic goals and the techniques how to operate GPS devices in this context. Therefore, the integration into a whole school semester seems reasonable. To prevent frustrations during the drawing process, it is important to discuss and adapt the individual concepts regarding scale and complexity.

\section{Acknowlegdement}

The project I AM HERE! at the BOKU University of Natural Resources and Life Sciences, Vienna was funded by the research programme Sparkling Science of the Austrian Federal Ministry of Science and Research. The authors want to thank Jasmin Opitz and Günter Klausberger, teachers at Bundesrealgymnasium Wien XIX, for their huge effort in supporting the project and all participating students for their enthusiasm.

\section{References}

AHAMER, G. \& RAUCH, H. (2006), Von “vertikaler" zu "horizontaler” Didaktik - Globalen Wandel mittels Diskursen "verweben". Zeitschrift für Hochschulentwicklung ZFHE 1, 127-147.

DeR STANDARD (2012), "YOLO" ist das deutsche Jugendwort 2012 [WWW Document: http://derstandard.at/1353207303343, 24.01.2013].

von Foerster, H. \& PöRKSen, B. (2003), Wahrheit ist die Erfindung eines Lügners: Gespräche für Skeptiker. Heidelberg, Carl-Auer-Systeme Verlag.

Goldsworthy, A. \& Friedman, T. (2008), Time: Andy Goldsworthy. London, Thames \& Hudson, Limited, 204 p. 
Gryl, I., JeKel, T. \& Donert, K. (2010), GI and Spatial Citizenship, In: JeKEL, T., KolLER, A. \& DONERT, K. (Eds.), Learning with Geoinformation V - Lernen Mit Geoinformation V. Heidelberg, Wichmann Verlag.

HARLey, J. B. (1992), Deconstructing the map. Cartographica, 26 (2), 1-20.

Lauriault, T. P. \& WoOD, J. (2009), GPS Tracings - Personal Cartographies. The Cartographic Journal, 46 (4), 360-365.

Mitchell, K. \& Elwood, S. (2012), Engaging Students through Mapping Local History. Journal of Geography, 111 (4), 148-157.

PARKS, L. (2001), Cultural Geographies in Practice Plotting the personal: Global Positioning Satellites and interactive media. Cultural Geographies, 8, 209-222.

Robinson, A. H. \& PetcheniK, B. B. (1976), The Nature of Maps: Essays Toward Understanding Maps and Mapping. Chicago, University of Chicago Press, 138 p.

Roelstraete, D. (2010), Richard Long: A Line made by Walking. London, Afterall Books, $104 \mathrm{p}$.

Schauppenlehner, T., Muhar, A., Höglhammer, A., Eder, R. \& Taczanowska, K. (2012), I AM HERE! Participatory exploration of the recreational behavior of adolescents using a multiple media approach, In: Fredman, P., STENSEKe, M., LiLJENDAHL, H., Mossing, A. \& LAven, D. (Eds.), The 6th International Conference on Monitoring and Management of Visitors in Recreational and Protected Areas: Outdoor Recreation in Change - Current Knowledge and Future Challenges, Friluftsliv i Förändring. Stockholm, 184-185.

Schauppenlehner, T., Muhar, A., Taczanowska, K. \& Eder, R. (2011), Concept for the integration of multiple media for participatory exploration of the spatial behaviour of adolescents, In: JeKEL, T., KOLLER, A., DONERT, K. \& VoGLER, R. (Eds.), Learning with GI 2011: Implementing Digital Earth in Education. Berlin/Offenbach, Wichmann Verlag, 70-78.

StARK, H. J. (2012), Spatial Pattern Analysis of Secondary School Students' Leisure Tracks. In: Jekel, T., CAR, A., Strobl, J. \& Griesebner, G (Eds.), GI_Forum 2012: Geovizualisation, Society and Learning. Berlin/Offenbach, Wichmann Verlag, 336-344.

Tufnell, B., Wilson, A., McKibBen, B. \& ScotT, D. K. (2002), Hamish Fulton: Walking Journey. London, Tate Publishing, $156 \mathrm{p}$.

URBAN DiCTIONARY (2012), Urban Dictionary: Term YOLO [WWW Document: http://www.urbandictionary.com/define.php?term=yolo, 24.01.2013].

Ursprung, P. (2003), Grenzen der Kunst: Allan Kaprow und das Happening, Robert Smithson und die Land Art. München, Verlag Silke Schreiber, 405 p.

Vygotsky, L. (1978), Mind in Society: The development of higher psychological processes. Cambridge, Harvard University Press.

Wood, J. (2010), Warwick Arts Centre: Traverse Me. [WWW Document: http:/www.warwickartscentre.co.uk/events/visual-arts/traverse-me, 24.01.2013]. 